\title{
Organisational capital and hospital performance in Hungary*
}

Antónia Hüttl

Senior Research Advisor Kopint-Tárki Institute for Economic Research;

Editor in Chief

Hungarian Statistical Review E-mail: Antonia.Huttl@ksh.hu

Ágnes Nagy
Senior Research Advisor
Kopint-Tárki Institute for Eco-
nomic Research
E-mail: agnes.nagy@kopint-
tarki.hu

Ágnes Nagy

Kopint-Tárki Institute for Eco-

tarki.hu
The paper presents a case study that explores the possibilities of measuring own-account OC (organisational capital) and its impact on hospital performance in Hungary. The authors' dataset consists of the 2010-2013 time series of 58 general hospitals owned by the government. Investment in own-account OC is measured both in a narrow sense and in a broad sense, depending on the range of employees contributing to OC. According to the estimates, the average stocks of OC in the examined period varied between $2.5 \%$ and $4.3 \%$ of the wages of all employees, provided that only managers and other executives were engaged in creating OC (narrow approach), and between $11.3 \%$ and $12.3 \%$ when employees in several non-managerial positions were also considered as contributors to OC (broad approach). The analysis provides some evidence that in the latter case, OC stocks have a slight positive effect on clinical performance measured by the cost weighted number of activities. In the narrow approach, a positive correlation could be detected if higher values were attached to the DRGs (diagnosisrelated groups) of complicated interventions and of treatment of serious diseases.

KEYWORDS:

Hospital performance.

Active care.

Organisational capital.

DOI: 10.20311/stat2017.K21.en128

* The project has received funding from the European Union's Seventh Framework Programme for Research and Technological Development under grant agreement No. 612774. 
The Hungarian study is part of a research conducted within the SPINTAN project (http://www.spintan.net/about-spintan/) on the impact of OC on hospital performance in three countries: Germany, Hungary, and England. The research teams in each country have attempted to use as much as possible a common methodology for both data definitions and statistical techniques. Investments in own-account OC are defined by them in terms of expenditures on personnel who generated this asset. Hospital performance is measured as an index of overall output based on activities undertaken by general (rather than specialised) hospitals; and the hospital production function is estimated including inputs and a number of common control variables.

In the study, the term "organisational capital" is used as adopted in the mainstream literature. OC is widely acknowledged as an important part of firm-specific knowledge assets, a great part of which is own account, produced by the employees. Investment in own-account OC could be measured by the compensation of employees in proportion to their working time spent on creating OC. According to the CHS approach (Corrado-Hulten-Sichel [2005], [2009]), only managers and other executives are engaged in generating OC, and $20 \%$ of their working time (valued by the compensation received) is used for this purpose. In the study of the OECD Directorate for Science, Technology and Industry (Squicciarini-Le Mouel [2012]), a broader concept is suggested according to which employees in several nonmanagerial positions may also contribute - to varying degrees - to producing OC.

As it is widely cited, OC as an enterprise-specific intangible asset extends the production possibilities of the enterprise. In health care, it means that hospitals owning more OC than others can provide - with the same inputs - a higher volume of health services. OC is a special kind of intangible asset in the sense that it is not marketable. Some of its components can be acquired on the market, for example, in the form of employee training, but their majority is produced by the enterprise. As OC is firm specific, it does not have a separate market value; its value is imbedded in the value of the enterprise as a whole and can be estimated only by costs and expenditure on its acquisition.

The production of own-account OC is a secondary activity of the enterprise, which is presently not included in the macroeconomic aggregates. It is assumed that it is an activity without any capital and intermediate inputs, and the value of its output is equal to the payments to the employees engaged in the creation of OC. On the current accounts, one should make estimates on the creation of such assets both as a secondary productive activity of the enterprise concerned and as an investment on the use side. To measure the impact of OC on performance, the volume of its stocks 
should be estimated. It is widely assumed that changes in the capital input are proportional to changes of stocks in constant prices when a geometric depreciation profile is applied. To estimate the value of stocks of assets with a PIM (Perpetual Inventory Model), long-term investment series are required, and one should make assumptions about the life cycle of the assets.

\section{Data sources to measure $\mathrm{OC}$ and its impact}

The hospital-level micro dataset of this analysis is compiled from various sources. In Hungary, there are abundant data at hospital level, collected for different purposes by various government agencies. Compilation of (especially economic) statistics is, in most cases, only a secondary way of using available data. Therefore, their contents and classifications are not tailored to the statistical needs. In addition, not all data collected are used regularly for administrative purposes, so a considerable number of primary data are not checked and corrected properly.

The main characteristics of inpatient care facilities financed by NHIF (National Health Insurance Fund) are presented in Table 1.

Table 1

Characteristics of inpatient care facilities (financed by NHIF) in Hungary, 2003, 2005, 2010, and 2013

\begin{tabular}{l|c|c|c|c}
\hline \multicolumn{1}{c|}{ Characteristic } & 2003 & 2005 & 2010 & 2013 \\
\hline Number of service providers & 180 & 184 & 178 & 172 \\
\hline Number of hospital beds & 79715 & 79394 & 71183 & 68995 \\
\hline Number of hospital beds per 10 000 of population & 78.7 & 78.7 & 71.2 & 69.7 \\
\hline Number of patients discharged (thousand) & 2749 & 2800 & 2458 & 2385 \\
\hline Number of nursing days (million) & 23.1 & 22.7 & 19.9 & 19.1 \\
\hline Occupancy rate of beds (\%) & 79.41 & 78.48 & 76.44 & 75.79 \\
\hline Average length of stay (days) & 8.36 & 8.09 & 8.06 & 7.90 \\
\hline Mortality rate (\%) & 2.86 & 2.81 & 3.23 & 3.36 \\
\hline
\end{tabular}

Note. There are also some small size inpatient facilities (e.g. in cosmetic surgery) that are not financed by NHIF.

Source: HCSO and NHIF statistics.

As Table 2 shows, the vast majority of inpatient care facilities are owned by the government. 


\begin{tabular}{|c|c|c|c|c|c|c|}
\hline \multirow[b]{2}{*}{ Type of owner } & \multicolumn{6}{|c|}{ Characteristic } \\
\hline & $\begin{array}{l}\text { Number of } \\
\text { inpatient care } \\
\text { facilities }\end{array}$ & $\begin{array}{l}\text { Number of } \\
\text { hospital beds }\end{array}$ & $\begin{array}{l}\text { Number of } \\
\text { patients } \\
\text { discharged } \\
\text { (thousand) }\end{array}$ & $\begin{array}{l}\text { Occupancy } \\
\text { rate of beds } \\
(\%)\end{array}$ & $\begin{array}{c}\text { Average } \\
\text { length of stay } \\
\text { (days) }\end{array}$ & $\begin{array}{c}\text { Mortality rate } \\
(\%)\end{array}$ \\
\hline Total & 174 & 68440 & 2366.2 & 74.74 & 7.98 & 3.41 \\
\hline \multicolumn{7}{|l|}{ of which: } \\
\hline Central government & 102 & 54475 & 1800.6 & 74.17 & 8.29 & 3.70 \\
\hline Local government & 12 & 83 & 7.5 & 108.32 & 4.17 & 0.25 \\
\hline University & 4 & 7363 & 375.3 & 72.3 & 5.17 & 1.95 \\
\hline Church & 9 & 1437 & 28.5 & 74.53 & 13.8 & 4.71 \\
\hline Other (private) company & 47 & 5082 & 154.3 & 82.00 & 9.81 & 3.53 \\
\hline
\end{tabular}

Source: HCSO and NHIF statistics.

To make a comparison, government-owned general hospitals are selected from all inpatient care facilities. General hospitals are such inpatient care facilities that have at least a department of surgery, gynaecology and general internal medicines. It should be noted that the selected hospitals do no constitute a random sample. They cover the total population of those general inpatient care providers whose all input data needed for the model are available and whose output can be measured by DRGs.

The Hungarian database consists of 58 general hospitals that were functioning in the whole period of 2010-2013. The database has been compiled from the following data sources:

Annual financial reports of budget institutions submitted to the State Treasury. As these very detailed reports are uniform and are prepared not just by health care providers but by all budget units, sometimes it is not clear what is the content of some of the categories used in the questionnaires, in the context of health care provision. (For instance, the questionnaire classifies positions in health sector such as standard posts in public administration, which are less relevant in health care provision.) Annual financial reports serve as a source not only for most of our input data but also for the production account of general government sector in the national accounts.

Statistical tables presented on the website of NHIF. They provide information, for example, on the size of hospitals (number of beds) as well as on the main composition and financing of their services. The sources of these tables are statistical reports on hospital beds and patient turnover and monthly reports prepared by the hospitals for NHIF on their inpatient care performance. 
Data on activities by DRGs at hospital level received from NHIF. This source contains data on the number of cases, sum of DRG points, length of nursing days, mortality rate, etc.

Statistical data collected by the State Secretariat for Healthcare of the Ministry of Human Resources on employment and wages in the health sector and presented on its website.

Various statistical surveys conducted by the Hungarian Central Statistical Office to substitute missing values.

According to Hungarian legislation, all these data on hospitals are public.

Tables 3 and 4 compare the main characteristics of Hungarian inpatient care facilities (financed by NHIF) with those of the selected hospitals. As the figures demonstrate, the hospitals included in our analysis cover about two thirds of all inpatient care facilities.

Table 3

\begin{tabular}{l|c|c|c}
\multicolumn{4}{c}{ Number of active beds in inpatient care facilities, 2010-2013 } \\
\hline Year & $\begin{array}{c}\text { Number of beds } \\
\text { in total active care }\end{array}$ & $\begin{array}{c}\text { Number of beds } \\
\text { in the active care of the } \\
\text { selected hospitals }\end{array}$ & Selected / total (\%) \\
\hline 2010 & 44179 & 31878 & 72.2 \\
\hline 2011 & 44137 & 31894 & 72.3 \\
\hline 2012 & 42211 & 31006 & 73.5 \\
\hline 2013 & 42258 & 32018 & 75.8 \\
\hline
\end{tabular}

Source: NHIF.

Number of DRG cases and sum of DRG points, 2010-2013

\begin{tabular}{c|c|c|c|c|c|c}
\hline \multirow{2}{*}{ Year } & \multicolumn{3}{|c|}{ Number of DRG cases } & \multicolumn{3}{c}{ Sum of DRG points } \\
\cline { 2 - 7 } & $\begin{array}{c}\text { in total active } \\
\text { care (thousand) }\end{array}$ & $\begin{array}{c}\text { in the active care } \\
\text { of the selected } \\
\text { hospitals (thou- } \\
\text { sand) }\end{array}$ & $\begin{array}{c}\text { Selected / total } \\
(\%)\end{array}$ & $\begin{array}{c}\text { in total active } \\
\text { care (thousand) }\end{array}$ & $\begin{array}{c}\text { in the active care } \\
\text { of the selected } \\
\text { hospitals (thou- } \\
\text { sand) }\end{array}$ & $\begin{array}{c}\text { Selected / total } \\
\text { (\%) }\end{array}$ \\
\hline 2010 & 2179.3 & 1506.6 & 69.1 & 2266.1 & 1455.2 & 64.2 \\
\hline 2011 & 2210.9 & 1530.9 & 69.2 & 2314.3 & 1485.3 & 64.2 \\
\hline 2012 & 2191.1 & 1547.0 & 70.6 & 2191.1 & 1503.0 & 68.6 \\
\hline 2013 & 2199.0 & 1602.6 & 72.9 & 2319.8 & 1565.6 & 67.5 \\
\hline
\end{tabular}

Source: NHIF, 
To measure investment in own-account OC, data on employment and salaries by responsibility and position are required. The Hungarian data sources provide an opportunity to measure own-account OC both in a narrow and in a broad sense:

1. In the financial reports of budget units, the position of an employee is classified by three dimensions:

- level of education (primary, secondary, tertiary) needed to hold the position,

- category of the position (whether it is a managerial/executive or a non-managerial position),

- type of duties of the position (principal, auxiliary, ancillary) within organisation.

It is worth noting that each budget unit has to report its employment figures in the same structure. This may facilitate the measurement of OC in other government activities as well.

2. The State Secretariat for Healthcare of the Ministry of Human Resources conducts annually a full-scope employment survey on all inpatient health care institutions. In the questionnaire, medical doctors, other professional staff and the other employed are distinguished and the number of the employed and wages are inquired about.

Employment figures are collected in head counts. The difference between these figures and their full-time equivalents in inpatient care of Hungary may not be significant.

\section{Measuring OC}

The study measures own-account OC following two different approaches. According to the narrow title-based approach, it is assumed that only employees holding executive/managerial positions produce OC, whereas the premise behind the broad task-based approach is that organisational capabilities are not limited to managers. All employees may perform tasks by which OC is created to varying degrees, depending on the content of the task. To provide comparable and plausible size of the investment in and stocks of OC in the two approaches, it is assumed that if more employees are able to create OC, they will spend less time on doing it (mainly in parallel with the provision of health care).

In the title-based approach (see also O'Mahony-Beghelli-Stokes [2016]), the CHS concept is strictly applied, and investment in own-account OC is measured as $20 \%$ of the compensation of managers, presuming that the same proportion of their 
working time is spent on management responsibilities. This concept distinguishes leading clinical professionals and general managers. In the task-based approach, by contrast, we make an assumption that doctors spend 9\%, other health professionals $6 \%$ of their working time on creating OC. In some calculations, other employees have been included as well, supposing that they spend $2 \%$ of their working time on producing OC. These ratios are similar to the ones applied by Schulz-Beckmann [2016] in the German case study of the SPINTAN project.

In 2013, on average, $5 \%$ of the staff was employed in managerial/executive positions in the Hungarian inpatient care facilities; the corresponding figure for the selected hospitals was about $4.5 \%$. These proportions refer to the hospitals as a whole, the number of managers and clinical executives in active care were not reported separately.

Table 5

Number of employees in the selected hospitals, 2010-2013 (title-based approach)

\begin{tabular}{r|r|r|r|r}
\hline Employee & 2010 & 2011 & \multicolumn{1}{|c|}{2012} & \multicolumn{1}{c}{2013} \\
\hline Clinical executive & 2217 & 2256 & 2314 & 2359 \\
\hline General manager & 533 & 560 & 580 & 582 \\
\hline Other employee & 60651 & 61493 & 61672 & 66264 \\
\hline Total & 63401 & 64309 & 64566 & 69205 \\
\hline
\end{tabular}

Source: Reports to the State Treasury.

In the selected hospitals, the percentage of doctors was $14.3 \%$ in the total number of employees in 2013, while the number of the qualified staff accounted for $51 \%$. Table 6 presents the relevant numbers and proportions.

To estimate OC stocks, a simplified PIM has been applied. We estimated several versions with different depreciation rates that depend on the number of years during which the person creating OC is employed in the same hospital. The core estimates apply a depreciation rate of $40 \%$ for general managers and $30 \%$ for clinical executives. As far as the leading clinical professionals in Hungary are concerned, the latter rate may be too high if the frequency of voluntary separation is taken into account.

Investment time series in constant prices were calculated following the changes in the number of employees creating OC and the changes in their real wages (deflated by the GDP deflator). To estimate an opening stock at the beginning of 2010, the investment series were back-casted, assuming that in each hospital the average growth rate of OC in the 2010-2013 period was valid also for the previous years. 
Number of employees in the active care of the selected hospitals and its share in total, 2010-2013 (task-based approach)

\begin{tabular}{|c|c|c|c|c|}
\hline \multirow{2}{*}{ Employee } & 2010 & 2011 & 2012 & 2013 \\
\hline & \multicolumn{4}{|c|}{ yearly average } \\
\hline & \multicolumn{4}{|c|}{ Employee } \\
\hline Doctor & 6794 & 7060 & 6769 & 7138 \\
\hline Other health professional & 22846 & 24309 & 24047 & 25521 \\
\hline Other employee & 18886 & 17781 & 20894 & 17429 \\
\hline \multirow[t]{2}{*}{ Total } & 48526 & 49150 & 51710 & 50088 \\
\hline & \multicolumn{4}{|c|}{ Share in total $(\%)$} \\
\hline Doctor & 14.0 & 14.4 & 13.1 & 14.3 \\
\hline Other health professional & 47.1 & 49.5 & 46.5 & 51.0 \\
\hline Other employee & 38.9 & 36.2 & 40.4 & 34.8 \\
\hline Total & 100.0 & 100.0 & 100.0 & 100.0 \\
\hline
\end{tabular}

Note. Here and in the tables hereafter, the deviations from 100.0 or from the total result from rounding. Source: Statistical reports on employment and wages in the health care sector.

Table 7

OC stocks as a percentage of total compensation of employees in the selected hospitals, 2010-2013

\begin{tabular}{l|r|r|r|r}
\hline \multicolumn{1}{c|}{ Approach } & 2010 & 2011 & \multicolumn{1}{c}{2012} & \multicolumn{1}{c}{2013} \\
\hline Title-based & 2.48 & 3.75 & 3.86 & 4.33 \\
\hline Task-based & 11.24 & 11.98 & 11.27 & 12.34 \\
\hline
\end{tabular}

Source: Own calculations based on reports to the State Treasury and on statistical reports to the State Secretariat for Health of the Ministry of Human Resources on employment and wages in the health care sector.

Concerning the size of OC stocks, there are considerable differences between the two approaches, which seem, at first glance, hardly acceptable. The OECD study (Squicciarini-Le Mouel [2012]) estimates for the US at the national level an about twofold difference between occupations included in title-based and task-based approaches, but inpatient health care is an exception. Figure 4 in the OECD study (Squicciarini-Le Mouel [2012] p. 22.) shows that in the US, the largest difference between managers and other organisational occupations occurs in the health care their ratio may be even larger than the ones in our study. Nevertheless, the broad 
classification of occupations applied by hospitals in public Hungarian health statistics is not really appropriate to select the staff contributing to OC creation. If a more specified categorisation were available, the coverage of the staff engaged in OC generation could be restricted.

Table 8

OC investment in the selected hospitals and in their active care, 2010-2013 (title-based approach)

\begin{tabular}{l|c|c|c|c|c|c}
\hline \multirow{2}{*}{ Year } & \multicolumn{4}{|c|}{ Selected hospitals } & \multicolumn{2}{c}{ Active care of the selected hospitals } \\
\cline { 2 - 7 } & Clinical & General & Total & Clinical & General & Total \\
\cline { 2 - 7 } & \multicolumn{5}{|c|}{ million HUF (2010 price level) } \\
\hline \multirow{2}{*}{2010} & 1676.8 & 433.1 & 2109.8 & 1180.1 & 304.6 & 1484.7 \\
\hline 2011 & 1841.7 & 478.2 & 2319.8 & 1305.8 & 338.8 & 1644.6 \\
\hline 2012 & 2023.5 & 528.4 & 2551.9 & 1435.6 & 375.0 & 1810.6 \\
\hline 2013 & 2256.8 & 593.1 & 2849.9 & 1618.1 & 426.0 & 2044.1 \\
\hline
\end{tabular}

Note. Investment rate: $20 \%$ of the real compensation of managers.

Source: Own calculations based on reports to the State Treasury.

Table 9

OC stocks in the selected hospitals and in their active care, 2010-2013 (title-based approach)

\begin{tabular}{l|c|c|c|c|c|c}
\hline \multirow{2}{*}{ Year } & \multicolumn{4}{|c|}{ Selected hospitals } & \multicolumn{2}{c}{ Active care of the selected hospitals } \\
\cline { 2 - 7 } & Clinical & General & Total & Clinical & General & Total \\
\cline { 2 - 7 } & \multicolumn{7}{|c|}{ million HUF (2010 price level) } \\
\hline \multirow{2}{*}{2010} & 1892.2 & 487.2 & 2379.5 & 1332.4 & 342.8 & 1675.3 \\
\hline 2011 & 3166.2 & 770.5 & 3936.7 & 2247.4 & 546.6 & 2793.9 \\
\hline 2012 & 4239.9 & 990.7 & 5230.5 & 3010.8 & 703.9 & 3714.7 \\
\hline 2013 & 5224.7 & 1187.5 & 6412.2 & 3745.9 & 853.1 & 4599.0 \\
\hline
\end{tabular}

Note. PIM: the investment rate is $20 \%$ of the real compensation of managers. The depreciation rate is $30 \%$ for clinical managers and $40 \%$ for general managers, using a geometric profile.

Source: Own calculations based on reports to the State Treasury.

In the title-based approach, OC stocks showed a sharp increase (on average, $35.3 \%$ per year) between 2010 and 2013, but, according to the task-based method, the growth was much more moderate, only $12.6 \%$ annually. The difference may be 
partly explained by the fact that the institutional reorganisation during the examined period could affect heavily the number of managers and less the coverage of the complete professional staff as such.

The volume levels of investment and stocks of OC are presented in Tables 8-10. The figures compiled at hospital level have been adjusted to active care proportionally to the cost shares financed by health insurance.

OC investment and stocks, total earnings and number of employees in the active care

of the selected hospitals, 2010-2013

(task-based approach)

\begin{tabular}{l|c|c|c|c|c|c}
\hline \multirow{2}{*}{ Year } & $\begin{array}{c}\text { Investment in } \\
\text { OC }\end{array}$ & OC stocks & Total earnings & $\begin{array}{c}\text { Employees in } \\
\text { active care }\end{array}$ & $\begin{array}{c}\text { Investment in OC } \\
\text { / total earnings }\end{array}$ & $\begin{array}{c}\text { OC stocks / total } \\
\text { earnings }\end{array}$ \\
\cline { 2 - 7 } & \multicolumn{3}{|c|}{ million HUF } & head & \multicolumn{2}{|c}{$\%$} \\
\hline 2010 & 5368 & 11920 & 106018 & 48526 & 5.1 & 11.2 \\
\hline 2011 & 5715 & 12867 & 107426 & 49150 & 5.3 & 12.0 \\
\hline 2012 & 7121 & 14841 & 131696 & 52622 & 5.4 & 11.3 \\
\hline
\end{tabular}

Note. The investment rate is $9 \%$ of the real compensation of medical doctors and $6 \%$ of that of other professional staff. PIM: the depreciation rate of OC stocks is $35 \%$, using a geometric profile. Data on employment and earnings refer to the employees in active care.

Source: Own calculations based on the reports of the State Secretariat for Healthcare of the Ministry of Human Resources on employment and wages.

\section{Measuring the impact of $\mathrm{OC}$ on hospital performance}

As it is widely accepted, capital input is proportional to the volume of stocks. We measure the impact of $\mathrm{OC}$ on hospital performance with the correlation between OC stocks and hospital output. In the basic specification, hospital output has been measured by the case-mix index multiplied by the number of cases.

The core model specification is the following:

$$
Y_{i t}=\alpha+\beta \cdot L_{i t}+\gamma \cdot M_{i t}+\pi I N T_{i t}+\delta_{n} Z_{n i t}+e_{i t},
$$

where $Y_{i t}$ denotes the level of services provided by hospital $i$ in year $t ; L_{i t}$ is the labour input measured by the number of employees; $M_{i t}$ is intermediate input (pur- 
chased materials and services); $I N T_{i t}$ refers to the stocks of own-account OC (both in the title-based and in the task-based approaches; in some title-based model variants, we distinguished clinical executives and general managers); $Z_{\text {nit }}$ are control variables (i.e. number of beds in active care, average length of stay in active care, age of patients over 70, share of females in the total number of patients, GDP per capita by counties, and unemployment rate by counties). Such as in the German model (Schulz-Beckmann [2016]), the level of service output is measured by the product of multiplying the number of activities/cases and the case mix index of the hospital. This kind of output measure is correct mainly in a cross sectional analysis. However, any changes in the weights attached to various DRGs may distort the comparisons in time series. (The secondary output of own-account OC is not included in the specification.)

The general characteristics of our variables are the following:

The variables are specified in levels: the level of hospital performance is explained by the amount of labour input, other running costs and the services provided by own-account OC. (Control variables are expressed in various units of measurement.)

All inputs recorded in values have been deflated to 2010 price level. A GDP deflator has been applied for all variables.

While (DRG-based) output/performance figures refer to active care, input data are relevant to the total costs of the hospital. For instance, we know the number of managers of a health care institution, but we do not know the number of managers working in its active care. To eliminate such differences, we have divided the input figures proportionally, using the cost shares financed by NHIF. (NHIF reports how much was spent on financing active care, long-term care, outpatient care, etc. at hospital level.)

If variables are specified in levels, the size effect influences heavily the significance of the estimates. To counterbalance the size effect, all output and input variables have been normalised by the number of beds in regression analysis. Both the dependent variable and predictors (except control variables) have been divided by the number of beds in active care (or the number of DRG cases).

Output has been adjusted by the hospital mortality rate.

\section{Results}

In the following, we present the 2010-2013 results of our cross sectional and pooled data regression analyses. 


\subsection{Cross sectional regression analysis}

Correlations between OC stocks and total clinical output. It is evident that OC stocks are strongly positively correlated with the clinical performance, indicating that larger hospitals having larger staff are providing a larger volume of care. In the 2010-2013 period, the Spearman coefficient of correlation was over 0.72 in the titlebased approach and over 0.95 in the task-based approach.

When the size effect was eliminated, and both OC stocks and output active care were normalised (divided by the number of activities/cases or by the number of beds), the results have been less clear-cut. Applying the task-based approach, we could detect a moderate, positive correlation between the volume of OC stocks and that of hospital output. Further investigations are required to find a conceptually justified way to separate the impact of labour input and that of own-account OC.

Table 11

Spearman rank correlation between OC stocks and total clinical output, 2010-2013

\begin{tabular}{l|c|c|c|c}
\hline \multirow{2}{*}{ Year } & \multicolumn{2}{|c|}{ Title-based, normalised OC stocks in active care } & \multicolumn{2}{c}{ Task-based, normalised OC stocks in active care } \\
\cline { 2 - 5 } & by number of DRGs & by number of active beds & by number of DRGs & by number of active beds \\
\hline \multirow{2}{*}{2010} & -0.378 & 0.124 & 0.277 & 0.551 \\
\hline 2011 & -0.387 & 0.116 & 0.279 & 0.561 \\
\hline 2012 & -0.349 & 0.204 & 0.357 & 0.527 \\
\hline 2013 & -0.373 & 0.022 & 0.262 & 0.489 \\
\hline
\end{tabular}

Note. Data are normalised by the number of DRG cases or by the number of active beds.

Source: Here and in the following tables, own calculations.

In the title-based approach, no positive correlation could be detected between the volume of OC and that of hospital output. This is, however, not surprising in the Hungarian health care as it is widely known that the Hungarian DRG points underfinance the DRGs of complicated, serious interventions. To manage departments performing such interventions, more executive capabilities are required, but this is not recognised in the points by which the output is evaluated.

Correlation between OC stocks and clinical output measured with cases of complicated interventions and the treatment of serious diseases. The distortion in the system of points used as weights to value clinical output may be a reason why no positive correlation can be found between OC stocks and clinical performance in the title-based approach. To eliminate this distortion, DRGs with more than two points have been selected, assuming that this set of activities covers the most complicated 
interventions and treatments of serious diseases. We refer to this subset of activities as complex cases and presume that they can be only treated in teamwork, in which usually executives are empowered to instruct team members. The organisation of such teamwork is considered part of the investment in OC.

To eliminate size effect, both OC stocks and the costs of performance have been normalised, divided by the number of DRGs (with over two points). In this version, the title-based OC indicates a moderate positive correlation with the selected performances. If the connection between complex activities and task-based OC is measured in a similar way, positive correlation can be proved only in that case when the figures are normalised by the number of beds in active care.

Table 12

\begin{tabular}{|c|c|c|}
\hline Year & $\begin{array}{l}\text { Title-based OC normalised } \\
\text { by the number of DRGs }\end{array}$ & $\begin{array}{l}\text { Task-based OC normalised } \\
\text { by the number of active beds }\end{array}$ \\
\hline 2010 & 0.290 & 0.420 \\
\hline 2011 & 0.341 & 0.380 \\
\hline 2012 & 0.371 & 0.437 \\
\hline 2013 & 0.347 & 0.354 \\
\hline
\end{tabular}

Results of the regression model. To reveal the explanatory strength of predictors, first we have calculated pairwise the Pearson coefficients of correlations between clinical performance and explanatory variables. Two basic variants are presented in Table 13. In variant A, all variables (except control variables) are normalised, divided by the number of DRGs (at hospital level). In variant B, the number of beds in active care is used to transform variables to a normalised form. As our dataset cannot be treated as a random sample, the results of the significance tests indicated in the correlation tables may be ignored (Wasserstein-Lazar [2016]).

The results show that both labour input and material costs are significantly correlated with clinical performance normalised either by the number of activities/cases or by the number of beds. In variants A and B, not the same control variables proved to be significant. As already mentioned, if clinical performance is measured by the sum of all DRGs, weighted with the points as financed by the health insurance, the variable is not correlated with OC defined in a narrow sense. It indicates that the organisational work performed by executives and managers is not appreciated in the value fixed by the health insurance. Applying the broad, task-based definition for OC, significant correlation with clinical performance can be proved in each year. Howev- 
er, in this case the relatively strong correlation between labour input and $\mathrm{OC}$ can cause a problem. (The Pearson coefficients are between 0.518 and 0.601.)

Pearson's coefficients of correlation between clinical performance and explanatory variables, 2010-2013

\begin{tabular}{|c|c|c|c|c|}
\hline Explanatory variable & 2010 & 2011 & 2012 & 2013 \\
\hline \multicolumn{5}{|c|}{ Variant A: Variables are normalised by cases } \\
\hline Clinical performance / cases & 1.000 & 1.000 & 1.000 & 1.000 \\
\hline Labour input in active care / cases & 0.266 & 0.268 & 0.206 & 0.264 \\
\hline Material costs in active care / cases & 0.655 & 0.605 & 0.682 & 0.681 \\
\hline Title-based approach: OC in active care / cases & -0.282 & -0.265 & -0.236 & -0.220 \\
\hline Task-based approach: OC in active care / cases & 0.303 & 0.297 & 0.374 & 0.301 \\
\hline Active beds & 0.715 & 0.708 & 0.768 & 0.710 \\
\hline Average length of stay & -0.039 & -0.050 & 0.031 & 0.004 \\
\hline Proportion of female patients & -0.626 & -0.594 & -0.626 & -0.698 \\
\hline Proportion of patients aged $70+$ & -0.233 & -0.231 & -0.175 & -0.164 \\
\hline Unemployment rate & -0.122 & -0.166 & -0.204 & -0.173 \\
\hline GDP / capita & 0.261 & 0.194 & 0.275 & 0.287 \\
\hline
\end{tabular}

Variant B: Variables are normalised by the number of active beds

\begin{tabular}{l|r|r|r|r} 
Clinical performance / active beds & 1.000 & 1.000 & 1.000 & 1.000 \\
\hline Labour in active care / active beds & 0.588 & 0.553 & 0.407 & 0.532 \\
\hline Material costs in active care / active beds & 0.703 & 0.661 & 0.609 & 0.669 \\
\hline Title-based approach: OC in active care / active beds & 0.109 & 0.109 & 0.288 & 0.039 \\
\hline Task-based approach: OC in active care / active beds & 0.470 & 0.458 & 0.494 & 0.375 \\
\hline Active beds & 0.568 & 0.538 & 0.385 & 0.534 \\
\hline Average length of stay & -0.395 & -0.411 & -0.302 & -0.400 \\
\hline Proportion of female patients & -0.297 & -0.245 & -0.147 & -0.393 \\
\hline Proportion of patients aged 70+ & -0.259 & -0.290 & -0.119 & -0.273 \\
\hline Unemployment rate & -0.164 & -0.250 & -0.202 & -0.176 \\
\hline GDP / capita & 0.389 & 0.349 & 0.352 & 0.369 \\
\hline
\end{tabular}

The cross sectional regression analysis shows similar findings. (See Tables 14 and 15.) 
oefficients of the cross sectional regression analysis, 2010-2013 (title-based OC stocks)

\begin{tabular}{l|c|c|c|c|c|c|c|c}
\hline \multirow{2}{*}{ Variable } & \multicolumn{2}{|c|}{2010} & \multicolumn{2}{|c|}{2011} & \multicolumn{2}{|c|}{2012} & \multicolumn{2}{|c}{2013} \\
\cline { 2 - 9 } & $B$ & $\beta$ & $B$ & $\beta$ & $B$ & $\beta$ & $B$ & $\beta$ \\
\hline
\end{tabular}

\begin{tabular}{|c|c|c|c|c|c|c|c|c|}
\hline \multicolumn{9}{|c|}{ Variant A: OC is normalised by cases } \\
\hline (Constant) & 0.696 & - & 0.477 & - & 0.508 & - & 0.716 & - \\
\hline Labour in active care / DRG cases & 0.084 & 0.096 & 0.015 & 0.021 & 0.002 & 0.003 & 0.079 & 0.080 \\
\hline Material costs in active care / DRG cases & 0.101 & 0.336 & 0.099 & 0.341 & 0.111 & 0.377 & 0.120 & 0.341 \\
\hline OC in active care / DRG cases & -0.017 & -0.041 & -0.016 & -0.041 & -0.019 & -0.047 & -0.021 & -0.053 \\
\hline Active beds & 0.000 & 0.367 & 0.000 & 0.379 & 0.000 & 0.378 & 0.000 & 0.371 \\
\hline Average stay in hospital & -0.006 & -0.034 & -0.012 & -0.068 & -0.017 & -0.103 & -0.017 & -0.093 \\
\hline Proportion of female patients & -0.017 & -0.291 & -0.016 & -0.272 & -0.019 & -0.307 & -0.018 & -0.279 \\
\hline Proportion of patients aged $70+$ & 0.000 & 0.011 & 0.000 & -0.001 & 0.002 & 0.051 & 0.000 & 0.002 \\
\hline Unemployment rate & 0.001 & 0.017 & -0.002 & -0.040 & 0.000 & -0.003 & -0.001 & -0.013 \\
\hline GDP / capita & 0.000 & 0.099 & 0.000 & 0.045 & 0.000 & 0.086 & 0.000 & 0.154 \\
\hline
\end{tabular}

\begin{tabular}{|c|c|c|c|c|c|c|c|c|}
\hline \multicolumn{9}{|c|}{ Variant B: OC is normalised by the number of active beds } \\
\hline (Constant) & 3.027 & - & 3.298 & $\mid-$ & 1.808 & - & 3.026 & - \\
\hline Labour in active care / active beds & 0.373 & 0.319 & 0.194 & 0.187 & 0.234 & 0.206 & 0.462 & 0.347 \\
\hline Material costs in active care / active beds & 0.081 & 0.192 & 0.077 & 0.183 & 0.152 & 0.358 & 0.113 & 0.232 \\
\hline OC in active care / active beds & 0.021 & 0.037 & 0.025 & 0.044 & 0.109 & 0.214 & -0.068 & -0.122 \\
\hline Active beds & 0.000 & 0.435 & 0.000 & 0.434 & 0.000 & 0.419 & 0.000 & 0.385 \\
\hline Average stay in hospital & -0.076 & -0.285 & -0.104 & -0.367 & -0.068 & -0.270 & -0.109 & -0.416 \\
\hline Proportion of female patients & 0.000 & 0.004 & 0.003 & 0.034 & 0.008 & 0.089 & 0.006 & 0.065 \\
\hline Proportion of patients aged $70+$ & 0.000 & -0.007 & -0.003 & -0.066 & -0.001 & -0.013 & -0.001 & -0.012 \\
\hline Unemployment rate & 0.002 & 0.029 & -0.008 & -0.124 & -0.006 & -0.082 & 0.001 & 0.015 \\
\hline GDP / capita & 0.000 & 0.155 & 0.000 & 0.125 & 0.000 & -0.001 & 0.000 & 0.282 \\
\hline
\end{tabular}

Note. Here and hereafter, $B$ denotes unstandardized coefficient, and $\beta$ indicates standardized coefficient. 
oefficients of the cross sectional regression analysis, 2010-2013 (task-based OC stocks)

\begin{tabular}{l|c|c|c|c|c|c|c|c}
\hline \multirow{2}{*}{ Variable } & \multicolumn{2}{|c|}{2010} & \multicolumn{2}{|c|}{2011} & \multicolumn{2}{|c|}{2012} & \multicolumn{2}{|c}{2013} \\
\cline { 2 - 9 } & $B$ & $\beta$ & $B$ & $\beta$ & $B$ & $\beta$ & $B$ & $\beta$ \\
\hline
\end{tabular}

\begin{tabular}{l|r|r|r|r|r|r|r|r} 
Variant A: OC is normalised by cases \\
(Constant) & 0.628 & \multicolumn{1}{c}{-} & 0.410 & \multicolumn{1}{c}{-} & 0.492 & \multicolumn{1}{c}{-} & 0.681 & - \\
\hline Labour in active care / DRG cases & 0.083 & 0.095 & 0.009 & 0.013 & -0.009 & -0.012 & -0.018 & -0.019 \\
\hline Material costs in active care / DRG cases & 0.104 & 0.346 & 0.102 & 0.351 & 0.109 & 0.372 & 0.126 & 0.359 \\
\hline OC in active care / DRG cases & -0.015 & -0.025 & -0.007 & -0.011 & 0.016 & 0.028 & 0.072 & 0.115 \\
\hline Active beds & 0.000 & 0.379 & 0.000 & 0.395 & 0.000 & 0.406 & 0.000 & 0.400 \\
\hline Average stay in hospital & -0.004 & -0.025 & -0.011 & -0.062 & -0.018 & -0.106 & -0.019 & -0.107 \\
\hline Proportion of female patients & -0.018 & -0.301 & -0.016 & -0.276 & -0.018 & -0.291 & -0.017 & -0.266 \\
\hline Proportion of patients aged 70+ & 0.001 & 0.016 & 0.000 & 0.005 & 0.002 & 0.049 & 0.000 & -0.012 \\
\hline Unemployment rate & 0.000 & 0.009 & -0.002 & -0.053 & -0.001 & -0.026 & -0.004 & -0.064 \\
\hline GDP / capita & 0.000 & 0.094 & 0.000 & 0.032 & 0.000 & 0.06 & 0.000 & 0.074 \\
\hline
\end{tabular}

\begin{tabular}{|c|c|c|c|c|c|c|c|c|}
\hline \multicolumn{9}{|c|}{ Variant B: OC is normalised by the number of active beds } \\
\hline (Constant) & 3.224 & - & 3.563 & - & 2.439 & - & 2.741 & - \\
\hline Labour in active care / active beds & 0.342 & 0.292 & 0.139 & 0.134 & 0.164 & 0.145 & 0.345 & 0.259 \\
\hline Material costs in active care / active beds & 0.073 & 0.173 & 0.065 & 0.153 & 0.136 & 0.321 & 0.129 & 0.266 \\
\hline OC in active care / active beds & 0.067 & 0.079 & 0.135 & 0.156 & 0.254 & 0.286 & 0.017 & 0.016 \\
\hline Active beds & 0.000 & 0.423 & 0.000 & 0.423 & 0.000 & 0.355 & 0.000 & 0.418 \\
\hline Average stay in hospital & -0.080 & -0.298 & -0.108 & -0.382 & -0.085 & -0.335 & -0.105 & -0.400 \\
\hline Proportion of female patients & 0.001 & 0.016 & 0.006 & 0.061 & 0.015 & 0.167 & 0.005 & 0.051 \\
\hline Proportion of patients aged $70+$ & -0.001 & -0.016 & -0.004 & -0.071 & -0.001 & -0.029 & -0.001 & -0.027 \\
\hline Unemployment rate & 0.002 & 0.036 & -0.009 & -0.131 & -0.007 & -0.102 & -0.002 & -0.028 \\
\hline GDP / capita & 0.000 & 0.151 & 0.000 & 0.079 & 0.000 & -0.076 & 0.000 & 0.229 \\
\hline
\end{tabular}

\subsection{Pooled data regression analysis}

To increase the number of observations, regression analysis has been carried out using pooled data. We have focused only on the task-based OC. The coefficient of OC stocks is positive in both variants, but there is a significant difference in its levels. The impact of OC on hospital performance is larger in the case of the $B$ variant (see Table 17), when the number of active beds has been used for normalisation. 
Model summary - Task-based OC normalised by cases, 2010-2013

\begin{tabular}{c|c|c|c|c}
\hline Model & $R$ & $R^{2}$ & Adjusted $R^{2}$ & $\begin{array}{c}\text { Standard error } \\
\text { of the estimate }\end{array}$ \\
\hline All variables* entered in a single step & $0.866(\mathrm{a})$ & 0.749 & 0.736 & 0.072286 \\
\hline
\end{tabular}

* Variables: Predictors (constant), Labour in active care / DRG cases (log), Material costs in active care / DRG cases (log). OC in active care / DRG cases (log), Active beds, Average stay in hospital (days), Proportion of female patients (\%), Proportion of patients aged 70+ (\%), Unemployment rate (\%), GDP / capita (HUF), Year 2010, Year 2011, Year 2012.

Table 17

Model summary - Task-based OC normalised by the number of active beds, 2010-2013

\begin{tabular}{c|c|c|c|c}
\hline Model & $R$ & $R^{2}$ & Adjusted $R^{2}$ & $\begin{array}{c}\text { Standard error } \\
\text { of the estimate }\end{array}$ \\
\hline All variables* entered in a single step & $0.853(\mathrm{a})$ & 0.727 & 0.712 & 0.115403 \\
\hline
\end{tabular}

* Variables: Predictors (constant), Labour in active care / active beds (log), Material costs in active care / active beds (log), OC in active care / active beds (log), Active beds, Average stay in hospital (days), Proportion of female patients (\%), Proportion of patients aged 70+ (\%), Unemployment rate (\%), GDP / capita (HUF), Year 2010, Year 2011, Year 2012.

Table 18

Pooled data regression coefficients, 2010-2013 (task-based OC stocks)

\begin{tabular}{l|c|c}
\hline Variable & $B$ & $\beta$ \\
\hline
\end{tabular}

Variant A: OC is normalised by cases

\begin{tabular}{l|r|r} 
(Constant) & 0.556 & \multicolumn{1}{c}{-} \\
\hline Labour in active care / DRG cases & 0.011 & 0.014 \\
\hline Material costs in active care / DRG cases & 0.109 & 0.357 \\
\hline OC in active care / cases & 0.007 & 0.014 \\
\hline Active beds & 0.000 & 0.380 \\
\hline Average length of stay & -0.012 & -0.067 \\
\hline Proportion of female patients & -0.018 & -0.305 \\
\hline Proportion of patients aged 70+ & 0.001 & 0.017 \\
\hline Unemployment rate & -0.001 & -0.023 \\
\hline GDP / capita & 0.000 & 0.078 \\
\hline Year 2010 & -0.001 & -0.003 \\
\hline Year 2011 & 0.006 & 0.017 \\
\hline
\end{tabular}

(Continued on the next page) 


\begin{tabular}{l|r|r}
\hline \multicolumn{1}{c|}{ Variable } & $B$ & $\beta$ \\
\hline Variant B: OC is normalised by the number of active beds \\
(Constant) & 3.128 & - \\
\hline Labour in active care / active beds (log) & 0.216 & 0.189 \\
\hline Material costs in active care / active beds (log) & 0.102 & 0.232 \\
\hline OC in active care / active beds (log) & 0.115 & 0.149 \\
\hline Active beds & 0.000 & 0.385 \\
\hline Average length of stay (days) & -0.097 & -0.361 \\
\hline Proportion of female patients (\%) & 0.004 & 0.044 \\
\hline Proportion of patients aged 70+ (\%) & -0.002 & -0.034 \\
\hline Unemployment rate (\%) & -0.003 & -0.045 \\
\hline GDP / capita (HUF) & 0.000 & 0.107 \\
\hline Year 2010 & 0.027 & 0.054 \\
\hline Year 2011 & 0.026 & 0.053 \\
\hline Year 2012 & 0.051 & 0.103 \\
\hline
\end{tabular}

\section{Summary and conclusions}

This Hungarian case study measures own-account OC following two approaches. According to the narrow title-based approach, only employees being in executive/managerial positions produce OC, while the broad task-based approach assumes that all employees may perform tasks in course of which OC is created to different degrees, depending on the content of the task.

In order to provide a comparable and plausible size of OC in both approaches, it was assumed in the task-based approach that employees spend less time doing organisational work. In the title-based method, we have applied CHS recommendations and measured investment in own-account OC as $20 \%$ of the compensation of executives/managers. In the task-based approach, it was assumed that doctors spent 9\%, other health professionals $6 \%$ of their working time on creating OC. These ratios, however, are not specific to Hungary because they are based on the corresponding German research (Schulz-Beckmann [2016]).

Our database consists of 58 general hospitals having comparable data for the period of 2010-2013. Almost three quarters of the active care beds have belonged to these hospitals.

The research has first estimated OC stocks in both approaches, which showed considerable differences: in 2013, the OC stocks were nearly three times higher in 
the case of the task-based approach than in that of the other one. At the same time, the value of OC stocks came up to about $12 \%$ of the compensation of all employees in the selected hospitals.

After estimating OC stocks, we have analysed the impact of OC on the clinical performance of hospitals. Several cross sectional statistics have been compiled. In the task-based approach, we could identify a slight positive correlation between OC stocks and the overall clinical performance; however, no positive correlation could be found in the title-based approach. We assume that better results would be achieved, if the clinical performance variable put more value on DRGs of complicated interventions and the treatment of serious diseases. Measuring clinical performance with DRGs over two points, a moderate positive correlation could be found between OC stocks and clinical performance.

\section{References}

Corrado, C. - Hulten, C. - Sichel, D. [2005]: Measuring capital and technology: an expanded framework. In: Corrado, C. - Haltiwanger, J. - Sichel, J. (eds.): Measuring Capital in the New Economy. Studies in Income and Wealth. Vol. 65. National Bureau of Economic Research. Cambridge. pp. 11-45. http://www.nber.org/chapters/c0202.pdf

Corrado, C. - Hulten, C. - Sichel, D. [2009]: Intangible capital and U.S. economic growth. Review of Income and Wealth. Series 55. No. 3. pp. 661-685. https://www.conferenceboard.org/pdf_free/IntangibleCapital_USEconomy.pdf

O’Mahony, M. - Begheldi, S. - Stokes, L. [2016]: Organisational Capital and Hospital Performance in England. SPINTAN Working Papers. No. 12. http://www.spintan.net/wpcontent/uploads/public/WP_12_OMahony_Beghelli_Stokes.pdf

Schulz, E. - Beckmann, L. [2016]: Hospital Performance and Intangible Investments. The Impact of Own Account Organizational Capital. SPINTAN Working Papers. No. 9. http://www.spintan.net/wp-content/uploads/public/WP_09_Schulz_Beckmann.pdf

SQuicciarini, M. - Le Mouel, M. [2012]: Defining and Measuring Investment in Organisational Capital: Using US Microdata to Develop a Task-based Approach. OECD Science, Technology and Industry Working Papers. No. 2012/05. OECD Publishing. Paris. http://dx.doi.org /10.1787/5k92n2t3045b-en

WASSERSTEIN, R. L. - LAZAR, N. A. [2016]: The ASA's statement on $p$-values: context, process, and purpose. The American Statistician. Vol. 70. No. 2. pp. 129-133. http://dx.doi.org/10.1080/00031305.2016.1154108 